\title{
The feasibility of implementing a pay-for-performance program in the treatment of alcohol/drug addiction: Implementation and initial results
}

\author{
Audrey A. Klein*1, Karen D. Lloyd ${ }^{2}$, Lisa M. Asper ${ }^{1}$ \\ ${ }^{1}$ Hazelden Betty Ford Foundation, Center City, MN, United States \\ ${ }^{2}$ HealthPartners, Bloomington, MN, United States
}

Received: April 18, 2016

Accepted: May 19, 2016

Online Published: June 12, 2016

DOI: $10.5430 /$ jha.v5n5p1

URL: http://dx.doi.org/10.5430/jha.v5n5p1

\begin{abstract}
Background: This paper discusses the design and implementation of a pay-for-performance (P4P) initiative within the context of alcohol and drug addiction treatment. Though the use of P4P programs to enhance the quality of health care services has been increasing for certain chronic health conditions, these programs have been underutilized by providers of addiction treatment.

Methods: Recently, as part of a new contractual agreement for patient care, a nationally-based alcohol/drug treatment provider collaborated with a major insurance payer to identify a set of metrics related to the quality of care. Selection of the metrics was guided by the Institute for Healthcare Improvement (IHI)'s Triple Aim, with measures representing the patient experience, patient engagement with services, and readmission to treatment services. Prior to the beginning of each contract year, targets for each metric were set based on historic baseline data, and the treatment provider was financially incentivized by the insurance payer to achieve the targets.

Results: A higher number of metrics targets were achieved in the second year of the contract compared to the first.

Conclusions: The experience of both organizations thus far demonstrates that implementation of P4P initiatives within addiction treatment is feasible, provided that both parties are committed to the success of the endeavor. Future studies should examine the efficacy of these programs with a research-based methodology.
\end{abstract}

Key Words: Pay-for-performance, Addiction treatment, Patient outcomes, Care quality

\section{INTRODUCTION}

Pay-for-performance (P4P) incentive strategies have been increasingly utilized in the healthcare industry. The primary goal of these strategies is to increase the quality and efficiency of care for patients by providing financial incentives to care providers. The Institute for Healthcare Improvement (IHI) has championed this cause from a historical perspective, pointing out that the U.S. healthcare system is the most expensive in the world, and outcomes of patients vary widely across a number of disease conditions. ${ }^{[1]}$ There is tremendous need to increase the health of individuals treated by healthcare organizations and reduce the burden of illness through coordinated, high quality care systems. The rationale behind $\mathrm{P} 4 \mathrm{P}$ approaches is that providing financial incentives to care providers will motivate them to optimize performance, so that patients may receive a high quality of

\footnotetext{
*Correspondence: Audrey A. Klein; Email: aklein@ hazeldenbettyford.org; Address: Hazelden Betty Ford Foundation, Center City, MN, 55012, United States.
} 
care at a reasonable cost. ${ }^{[2]}$ The IHI's approach focuses on 3 elements (sometimes called the "Triple Aim"): (1) improving the patient experience (with a focus on the quality of care and patient satisfaction); (2) improving the health of populations (via patient engagement with services and patient outcomes); and (3) reducing the cost of care. ${ }^{[2]}$ The IHI also created a set of metrics to measure an organization's performance as related to quality of care and tracking the effectiveness of care improvement efforts. These "Whole System Measures" are designed to accompany the organization's own measures and are not disease- or condition-specific. ${ }^{[3]}$

Many research studies examining the impact of $\mathrm{P} 4 \mathrm{P}$ programs on healthcare organization performance and patient outcomes have yielded positive results, though some report mixed findings. Van Herck and colleagues point out that the challenges in examining the impact of $\mathrm{P} 4 \mathrm{P}$ programs stem from the complexity and heterogeneity across programs. Programs differ in terms of the nature of the incentives, who is the direct recipient of the incentive (i.e., an individual practitioner or an entire healthcare organization or system), the nature of the patient population and healthcare condition of interest, and the type of metrics selected (e.g., patient outcomes, initiation of services, implementation of evidence based practices, etc.). ${ }^{[4]}$ Houle and colleagues reviewed 30 studies of $\mathrm{P} 4 \mathrm{P}$ remuneration with individual care providers and found that uncontrolled studies suggest that P4P increases the quality of care, but more rigorous controlled studies showed little to no impact. The healthcare conditions examined in these studies included cancer, diabetes, asthma and heart disease. ${ }^{[5]}$ Another review of over 120 studies found that regarding preventive care, the most positive findings occurred with diabetes, with several studies showing an impact of $\mathrm{P} 4 \mathrm{P}$ on quality improvement. Positive results were also found for smoking cessation and asthma, though none were found on the quality of care or outcomes for coronary heart disease. ${ }^{[4]}$ Another study examining the impact of P4P programs in acute care hospitals found that $\mathrm{P} 4 \mathrm{P}$ hospitals were more likely than control group hospitals to achieve high performance scores during the first 5 years of program implementation. ${ }^{[6]}$ Performance scores reflected whether the hospital met or exceeded specified standards of care in treating a number of disease conditions, including pneumonia, heart failure, myocardial infarction, and hip and knee replacements. In addition, the most dramatic improvements in care quality were found in $\mathrm{P} 4 \mathrm{P}$ hospitals that operated in less competitive markets, had strong financial performance, and employed large financial incentives. ${ }^{[6]}$

Though P4P initiatives have been implemented with providers of services for a number of chronic medical conditions, they have been infrequently utilized with providers of alcohol/drug addiction treatment. The Washington Circle is a group of national experts in the addiction field who were among the first to propose treatment quality measures. Their overall goal is to increase the effectiveness and quality of addiction treatment services through the use of performance measurement systems. They developed a set of performance measures and have collaborated with various stakeholders, particularly in the public sector, to encourage adoption of the measures. Several states have done so for their public programs, though variability exists in how the measures are used. ${ }^{[7,8]}$ Many measures focus on initiation of treatment services when warranted and on patient engagement with treatment once initiated. Research examining the impact of these measures on patient outcomes is mixed. One study examined administrative data from the Oklahoma Department of Mental Health and Substance Abuse Services; these data were linked to data from criminal justice agencies. Patients who initiated an outpatient substance abuse treatment episode and remained engaged in treatment were significantly less likely to be arrested or incarcerated in the year following treatment. ${ }^{[9]}$ A study examining adolescents attending substance use disorder treatment services found that those who regularly engaged in outpatient services were less likely than unengaged patients to use drugs or alcohol during a 6 month follow up. However, treatment engagement was unrelated to criminal behavior at follow up. ${ }^{[10]}$

Vandrey and colleagues used a pre/post study design to examine whether a P4P strategy involving financial compensation of substance abuse counselors would increase treatment utilization and retention in outpatient treatment. Patients attended a community substance abuse clinic for either alcohol or drug problems; the majority were referred by the criminal justice system for Driving Under the Influence (DUI), drug possession, or related offenses. The P4P manipulation was designed to increase both the number of treatment sessions attended and the percentage of patients who were still engaged in treatment at 90 days. Counselors of patients assigned to the $\mathrm{P} 4 \mathrm{P}$ condition received weekly bonus pay for each patient who attended treatment a given number of times during the study period. Compared to a treatment-as-usual condition, patients assigned to counselors in the $\mathrm{P} 4 \mathrm{P}$ condition attended significantly more therapy sessions during the first month and were significantly more likely to still be attending at 90 days. $^{[11]}$ Another study of 29 community-based adolescent substance abuse treatment facilities found that therapists who received financial compensation for implementation of evidence-based therapy practices exhibited greater treatment delivery competence than therapists in the control group. However, the P4P patients did not have better substance use outcomes than control patients. ${ }^{[12]}$ 


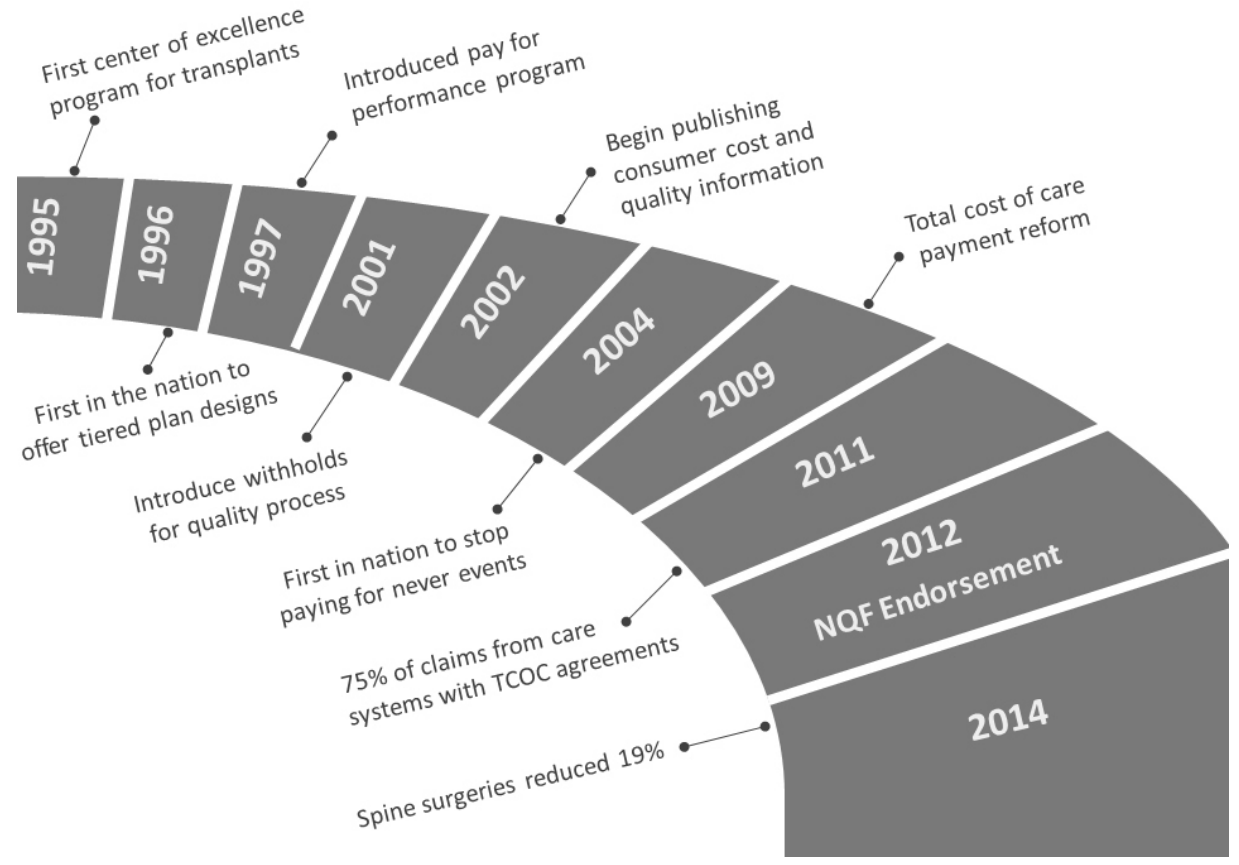

Figure 1. Payment methodology process improvement timeline
In sum, the implementation of $\mathrm{P} 4 \mathrm{P}$ programs to improve the quality and outcomes of addiction treatment has been lacking relative to programs for other chronic disease conditions. The purpose of this manuscript is to describe the development and implementation of a P4P initiative by a provider of alcohol/drug addiction treatment and a large insurance payer and report the initial results of the approach. The insurance payer has 20 years of leadership in payment reform and quality improvement (see Figure 1) and helped develop and apply this innovative application of $\mathrm{P} 4 \mathrm{P}$ principles to alcohol/drug addiction treatment. The two organizations piloted several P4P metrics aimed at measuring organizational performance of the treatment provider and patient engagement in care. Selection of the metrics was guided in large part by the IHI's Triple Aim and some metrics were similar to the Whole System Measures created and endorsed by the IHI. ${ }^{[3]}$ The overall goal was to build knowledge regarding how performance-based metrics can be implemented within addiction treatment, so that use of these measures and evaluation of their impact may gain additional traction in the field. Importantly, amicable collaboration between the payer and treatment provider was vital in the successful implementation of the initiative, and required transparency and commitment on both sides.

\section{MethodS}

As part of renewing a contract for patient care coverage with a major insurance payer, staff from a nationally-based addiction treatment provider worked with leadership of the payer to set up the P4P initiative. The health plan which guided the $\mathrm{P} 4 \mathrm{P}$ discussions applied several overarching principles to create the foundation and rationale of the endeavor (see Figure 2). On the payer side, processes included aligning payment incentives, making information actionable in the care delivery setting, and focusing on the entire patient population. On the care delivery side, the use of evidence-based practices within a patient-centered approach was paramount.

\section{Integration as our engine}

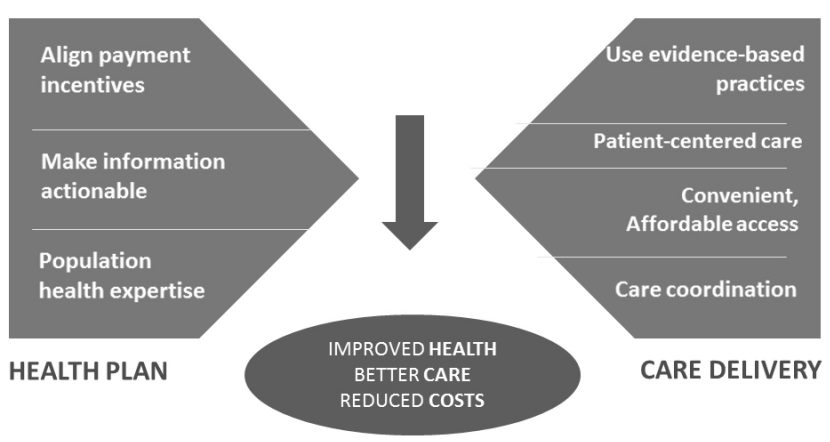

Figure 2. Structure of payment plan methodology and care delivery framework

As the organizations began a dialog about quality, experience and cost, it became evident that the process of collaboration itself was an important aspect of the initiative. The process of working together included establishing a number of collaborative conditions, including: (1) fostering the Triple Aim culture within both organizations, (2) listening sincerely and seeking to understand each other's organizational point of view, (3) cultivating trust among leaders of the organizations, 
which was developed over the course of a year of regular meetings on the topics of health improvement, patient experience and controlling the cost of healthcare, (4) mutual encouragement among workgroup members to tackle the relevant but difficult issues in performance measurement and improvement, and (5) celebrating successes together while considering and tackling new challenges that emerged.

The selection of metrics was largely guided by the Triple Aim and a consideration of the ongoing metrics collected by the addiction treatment provider as part of routine healthcare operations. Seven metrics were selected for the 2013 contract year; these are discussed in more detail below. Metrics represented patients from 2 programs offered by the treatment provider: adult residential (patients aged 25 to 79) and youth residential (patients aged 12 to 25). Both programs were based on the same 12-step treatment philosophy and the same key therapeutic practices, but the youth program was tailored toward a younger demographic (for example, youth were given an opportunity during treatment to do schoolwork). The treatment model used in both programs is described in detail elsewhere. ${ }^{[13,14]}$ Treatment is grounded in the philosophy of Alcoholics Anonymous and stresses the importance of the 12 steps in recovery from addiction. Substance addiction is seen as a progressive, primary disease (i.e., not caused by something else) and treatment focuses on complete abstinence. Treatment involves medical personnel, addictions counselors, psychologists, spiritual care counselors and wellness specialists and employs a mix of individual therapy, group therapy, informational lectures, reading and homework assignments, peer interaction and practice of the 12 steps. Detoxification and medication-assisted treatment are also utilized where medically appropriate. Patients are given continuing care plans prior to discharge and are strongly encouraged to attend 12 step fellowships such as Alcoholic Anonymus (AA) or Narcotic Anonymus (NA) after treatment.

Once the metrics for the 2013 contract were selected, historical data for each metric were pulled and compiled by research staff employed by the treatment provider. These data were used to determine the metric baseline, or current value, so that metric targets/goals for the year could be set at a certain level above the baseline value. For all metrics, the baseline value was the mean or average value of all prior data points for that metric. Target values for each metric were then decided upon via team discussion. In all cases, it was deemed important that the target value be higher than the baseline, and the amount of increase from baseline was decided somewhat intuitively. The increase was intended to be large enough to be clinically meaningful but modest enough that it was judged achievable by clinical staff of the treatment provider. In cases where the baseline result was lower than the most recent data point, the target value was set based on the last data point. Table 1 shows baseline results and 2013 target values for each metric.

Based on the 2013 results, which were reviewed and evaluated in early 2014, one of the metrics (frequency of posttreatment 12 step meeting attendance among youth) was adjusted for the 2014 contract year because that metric came from the treatment provider's administrative outcomes survey, and the follow up rate for the 6 month outcomes survey for youth residential was extremely low; causing the metric to be unreliable. The team replaced that metric with another metric for youth that represented patient engagement: the percentage of youth residential patients who were admitted to another treatment program (offered by the same provider) within 14 days of being discharged from the residential program. This program was either outpatient or day treatment and was recommended for patients where a longer period of engagement with formal services was warranted. All other metrics remained the same and new targets were set based on consideration of the 2013 end-of-year results. Table 2 shows the 2014 metrics, baseline and target values.

The financial aspect of the P4P arrangement involved the treatment provider identifying a "pool" of dollars at the beginning of each contract year which was then applied to the end-of-year results for the P4P metrics. This total metrics pool was negotiated at $4 \%$ of total revenues for 2013 and $5 \%$ of total revenues in 2014. The pool was then distributed evenly across the 7 metrics, such that each metric was associated with the same dollar amount. If the target/goal for a given metric was achieved at the end of the measurement period, then the treatment provider did not have to pay out of the pool. However, if the provider missed the target then the amount for that metric was paid out to the insurance payer.

\section{Measures}

Patient rating of quality of care. To assess the patients' perception of their care experience, they were asked the following question several days before discharge from the treatment program: "Please rate the overall quality of the care and services you received" (response scale: very good, good, fair, poor, very poor).

Patient rating of helpfulness of care. A second question was asked several days before program discharge to capture another aspect of the patient's experience: "Please rate the degree to which treatment helped you deal with your addiction problem" (same response scale as above). 
Table 1. 2013 performance metrics

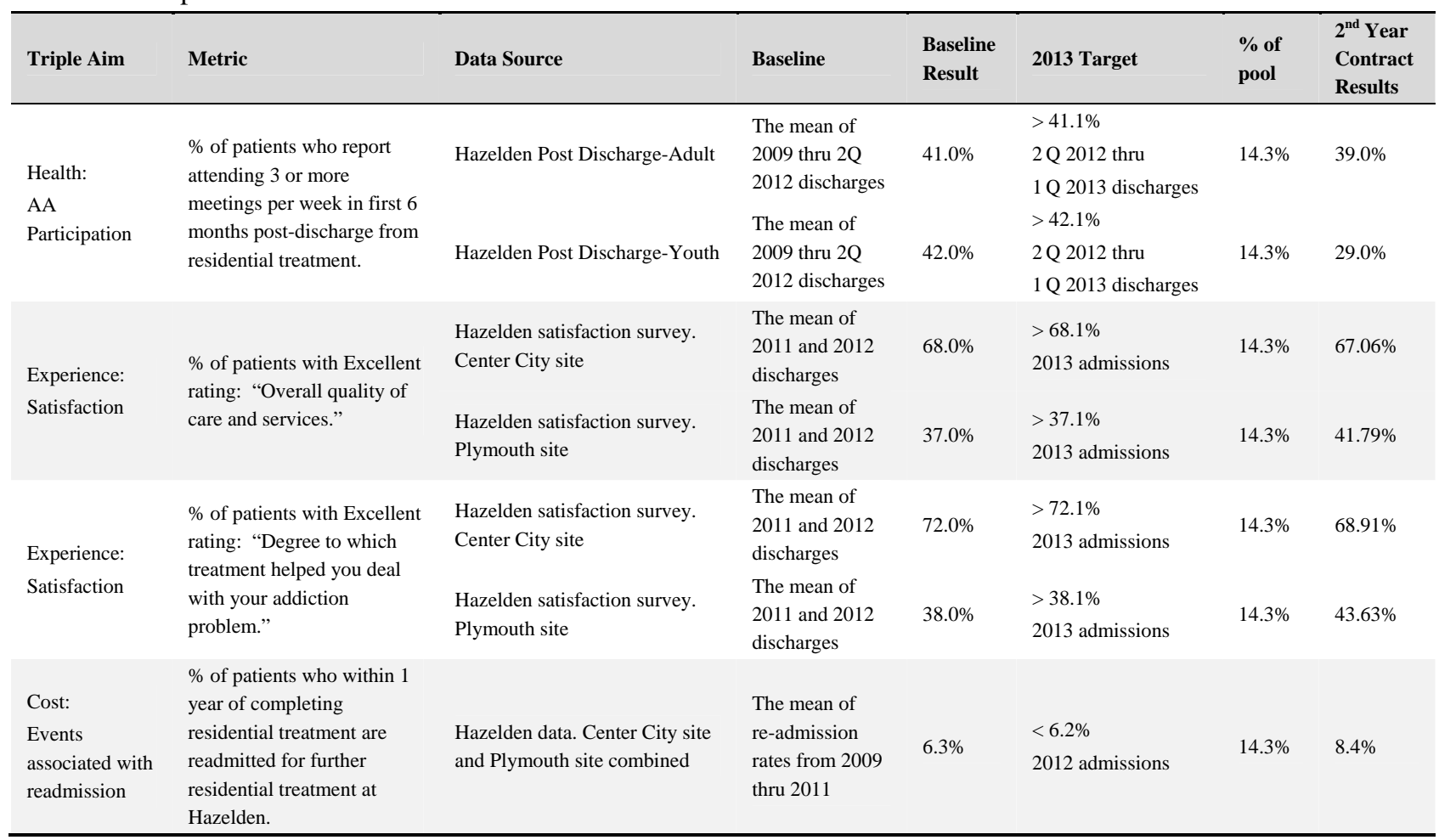

Table 2. 2014 performance metrics

\begin{tabular}{|c|c|c|c|c|c|c|c|}
\hline Triple Aim & Metric & Data Source & Baseline & $\begin{array}{l}\text { Baseline } \\
\text { Result }\end{array}$ & 2014 Target & $\begin{array}{l}\% \text { of } \\
\text { pool }\end{array}$ & $\begin{array}{l}3^{\text {nd }} \text { Year } \\
\text { Contract } \\
\text { Results }\end{array}$ \\
\hline $\begin{array}{l}\text { Health: } \\
\text { AA } \\
\text { Participation }\end{array}$ & $\begin{array}{l}\% \text { of patients who report } \\
\text { attending } 3 \text { or more meetings } \\
\text { per week in first } 6 \text { months } \\
\text { post-discharge from residential } \\
\text { treatment. }\end{array}$ & Hazelden Post Discharge-Adult & $\begin{array}{l}\text { The mean of } \\
2009 \text { thru 2Q } \\
2013 \text { discharges }\end{array}$ & $41.6 \%$ & $\begin{array}{l}>41.7 \% \\
\text { 2 Q 2013thru } \\
\text { 1 Q } 2014 \text { discharges }\end{array}$ & $14.3 \%$ & $42.3 \%$ \\
\hline $\begin{array}{l}\text { Health: } \\
\text { Patient } \\
\text { Engagement }\end{array}$ & $\begin{array}{l}\% \text { of Plymouth residential } \\
\text { patients who step down to } \\
\text { another Hazelden CD program } \\
\text { within } 2 \text { weeks of discharge. }\end{array}$ & Hazelden Post Discharge-Youth & $\begin{array}{l}\text { The value } \\
\text { predicted by the } \\
\text { trend line }\end{array}$ & $20.0 \%$ & $\begin{array}{l}>23.1 \% \\
2014 \text { admissions }\end{array}$ & $14.3 \%$ & $24.0 \%$ \\
\hline $\begin{array}{l}\text { Experience: } \\
\text { Satisfaction }\end{array}$ & $\begin{array}{l}\% \text { of patients with Excellent } \\
\text { rating: "Overall quality of care } \\
\text { and services." }\end{array}$ & $\begin{array}{l}\text { Hazelden satisfaction survey. } \\
\text { Center City site }\end{array}$ & $\begin{array}{l}\text { The mean of } \\
2011 \text { thru } 2013 \\
\text { discharges }\end{array}$ & $66.0 \%$ & $\begin{array}{l}>66.1 \% \\
2014 \text { admissions }\end{array}$ & $14.3 \%$ & $72.4 \%$ \\
\hline $\begin{array}{l}\text { Experience: } \\
\text { Satisfaction }\end{array}$ & $\begin{array}{l}\% \text { of patients with Excellent } \\
\text { rating: "Overall quality of care } \\
\text { and services." }\end{array}$ & $\begin{array}{l}\text { Hazelden satisfaction survey. } \\
\text { Plymouth site }\end{array}$ & $\begin{array}{l}\text { The mean of } \\
2011 \text { thru } 2013 \\
\text { discharges }\end{array}$ & $40.0 \%$ & $\begin{array}{l}>40.1 \% \\
2014 \text { admissions }\end{array}$ & $14.3 \%$ & $47.2 \%$ \\
\hline $\begin{array}{l}\text { Experience: } \\
\text { Satisfaction }\end{array}$ & $\begin{array}{l}\% \text { of patients with Excellent } \\
\text { rating: "Degree to which } \\
\text { treatment helped you deal with } \\
\text { your addiction problem." }\end{array}$ & $\begin{array}{l}\text { Hazelden satisfaction survey. } \\
\text { Center City site }\end{array}$ & $\begin{array}{l}\text { The mean of } \\
2011 \text { thru } 2013 \\
\text { discharges }\end{array}$ & $69.0 \%$ & $\begin{array}{l}>69.1 \% \\
2014 \text { admissions }\end{array}$ & $14.3 \%$ & $74.5 \%$ \\
\hline $\begin{array}{l}\text { Experience: } \\
\text { Satisfaction }\end{array}$ & $\begin{array}{l}\% \text { of patients with Excellent } \\
\text { rating: "Degree to which } \\
\text { treatment helped you deal with } \\
\text { your addiction problem." }\end{array}$ & $\begin{array}{l}\text { Hazelden satisfaction survey. } \\
\text { Plymouth site }\end{array}$ & $\begin{array}{l}\text { The mean of } \\
2011 \text { thru } 2013 \\
\text { discharges }\end{array}$ & $42.0 \%$ & $\begin{array}{l}>42.1 \% \\
2014 \text { admissions }\end{array}$ & $14.3 \%$ & $48.4 \%$ \\
\hline $\begin{array}{l}\text { Cost: } \\
\text { Events } \\
\text { associated } \\
\text { with } \\
\text { readmission }\end{array}$ & $\begin{array}{l}\% \text { of patients who within } 1 \\
\text { year of completing residential } \\
\text { treatment are readmitted for } \\
\text { further residential treatment at } \\
\text { Hazelden. }\end{array}$ & $\begin{array}{l}\text { Hazelden data. Center City site } \\
\text { and Plymouth site combined }\end{array}$ & $\begin{array}{l}\text { The mean of } \\
\text { re-admission } \\
\text { rates from } 2009 \\
\text { thru } 2013\end{array}$ & $6.7 \%$ & $\begin{array}{l}<6.6 \% \\
2012 \text { admissions }\end{array}$ & $14.3 \%$ & $6.5 \%$ \\
\hline
\end{tabular}


Post-treatment 12 step meeting attendance. The treatment model focuses on attendance at 12 step meetings as a key clinical ingredient in treatment success, and all residential patients have frequent attendance specified in their continuing care plan when leaving treatment. Hence, the frequency of meeting attendance after treatment is a measure of patient engagement with aftercare recommendations and a predictor of positive outcomes. ${ }^{[15]}$ As part of routine healthcare operations, the research department of the addiction treatment provider contacts patients discharged from adult and youth residential programs by phone roughly 1 , 6 and 12 months post-discharge to administer an outcomes survey. The survey consists of a number of questions relating to substance use, quality of life, daily life functioning (such as work or school performance), and engagement with 12 step fellowships. Each question on the survey references activities or behaviors that occurred in the timeframe spanning the date of the survey back to the date of treatment discharge. The following question from the 6 month survey was selected as an aftercare engagement metric: "How many 12 step meetings have you attended since you left the treatment facility?" The number reported by the patient was then divided by the number of weeks in the follow up period to get an estimate of meetings attended per week. The percent of patients in the sample who reported attending 3 or more meetings per week was then calculated and this percentage served as the P4P metric.

Readmission to residential treatment. The third Triple Aim is to lower the per capita cost of care, without sacrificing quality or patient safety. ${ }^{[3]}$ The two providers agreed that reducing the number of patients readmitted to residential treatment within a year of being discharged from the same program would help address the cost of care within the provider's patient population. By reducing the readmission rate and encouraging the provider to more closely examine the appropriate level of care for readmitted patients, the insurance payer would save additional costs associated with readmissions. For this metric, the number of patients who successfully completed residential treatment at one of the provider's facilities during a particular time period was identified. Successful completion of treatment was defined as leaving treatment "with staff approval", indicating the patient completed all clinical expectations and was judged ready to be discharged by clinical staff. The P4P team felt it important to qualify the metric as representing only patients who completed treatment, and thereby received maximal therapeutic benefit from the episode. On some occasions, patients leave treatment prematurely for a number of reasons, and both the treatment provider and the payer felt that the former should not be held accountable for the outcomes of those pa- tients. Among patients who completed residential treatment, the percentage readmitted to the same residential program within 1 year following discharge from the original episode was calculated and called the readmission rate. Unlike the other metrics, which were tracked and reported separately for adult and youth residential programs, this metric represented the 2 programs combined (for a total of $7 \mathrm{P} 4 \mathrm{P}$ metrics).

Youth residential patients: \% who continued programming after residential. In 2014, we replaced the posttreatment 12 step meeting attendance metric for youth with another measure of patient engagement. This metric, called the "stepdown" metric, was the percentage of youth residential patients who were admitted to either an intensive outpatient program or day treatment program (offered by the same provider) within 14 days of being discharged from the residential program. This metric represented continued engagement within the system of care and was consistent with the clinical model of the treatment provider, which was to refer patients to another level of "stepdown" care if clinically warranted. The metric also alleviated the small sample size issue that occurred with the 12 step meeting attendance metric for youth.

\section{RESUltS}

Tables 1 and 2 show year-end results for each of the two contract years. The patient population that provided each metric result was defined by either admit or discharge date from the residential program. It is important to note that the patient sample varied based on the nature of the metric, for example, because patient satisfaction is collected before patients leave treatment, these data are collected quickly and were available for an entire year of patients. However, the patient samples that provided the metrics for 12 step meeting attendance had a different date range, because these data were not eligible to be collected until roughly 7 months after the discharge date of the last person in the sample. In other words, for patients discharged in 2013, outcomes data for the last person discharged (on December 31) would not be available until 6-7 months after that date. As a result, we had to use patients who attended residential treatment at an earlier time period for the 12 step meeting attendance metric. Similarly, the readmission metric by definition required that we examine patients who had been out of residential treatment for up to one year; hence the same principle applied.

Table 1 shows that for the 2013 contract year, the treatment provider achieved 2 of the 7 metrics, and paid back to the insurance payer the amount withheld for the 5 missed metrics. In contrast, in 2014, the provider achieved 7 out of 7 metrics (see Table 2), and did not have to pay back any withheld dollars to the payer. 


\section{Discussion}

Recently, an addiction treatment provider collaborated with an insurance payer to develop a set of $\mathrm{P} 4 \mathrm{P}$ metrics designed to gauge the quality and cost of services. As the use of $\mathrm{P} 4 \mathrm{P}$ is a somewhat novel approach in the addiction field, the project team initially focused on building a firm foundation of mutual understanding and trust, assuring that the arrangement was a true collaboration receiving buy-in from both parties. This process required a great deal of time and commitment from all persons involved, and the nature of the collaboration evolved over the course of the initiative. For example, during the early years of the P4P initiative (the contract years reported here), the financial arrangement encompassed downside risk to the treatment provider. In other words, the provider had to pay out money to the insurance payer when metrics targets were missed. Under the contract currently in place, the treatment provider is incentivized to achieve $\mathrm{P} 4 \mathrm{P}$ targets via some upside risk, whereby success is rewarded with an increase in the rate of payment received from the insurance payer. This change reflects ongoing commitment and compromise on the part of both parties in creating a $\mathrm{P} 4 \mathrm{P}$ initiative that truly incentivizes both organizations to focus on improvement in the cost and quality of care.

The principal finding was that results obtained during the second year of the P4P initiative were much more positive than the first, with all targets being achieved. There are several possible explanations for this result, one being that it took considerable time and effort to implement the initiative during the first year. Implementation required educating clinical and operations staff about the initiative, obtaining buy-in from staff, and working to implement changes in clinical and business processes necessary to impact each metric. Specific tactics to achieve targets included creating organizational strategic plan goals around each metric and setting incentive goals for clinical leaders to achieve targets in their given area. In addition, for the first year of the $\mathrm{P} 4 \mathrm{P}$ initiative, some patients in the metric result group for post-treatment AA attendance had already been through treatment and some of their follow up period had already elapsed when the P4P process was implemented. As a result, the treatment provider was limited in its ability to strategically impact this particular metric. In 2014, staff were fully aware of this metric and had a greater opportunity to implement strategies and tactics to boost 12 step meeting engagement for all patients in the sample.

\subsection{Logistical challenges in implementing P4P metrics for addiction treatment}

It is important to note that the success in implementing these metrics was largely driven by the capability of the treatment

Published by Sciedu Press organization to provide data. In all cases, the data used for each metric were available because they were already being captured and collected by the provider as part of routine healthcare operations. Organizations that do not have extensive data collection systems in place for ongoing assessment and analysis of patient data may experience challenges in selecting and implementing P4P measures. The P4P metrics reported here supplement and extend those already in use in the addiction field, such as the Washington Circle measures. Indeed, thus far addiction treatment initiatives have focused heavily on access to treatment, utilization of treatment and retention in treatment. ${ }^{[7,9]}$ The metrics used here included patient engagement in treatment services and aftercare activities as well as patient perception of the quality of care and helpfulness of care, and to some extent, the cost of care (as captured in the residential treatment readmission metric). To have optimal impact, $\mathrm{P} 4 \mathrm{P}$ initiatives should include a wide variety of metrics that are collected in a valid, reliable way. This type of data collection requires time and resource allocation on the part of stakeholders (providers and payers).

Though the research department of the treatment facility reported in this paper routinely collects post-treatment substance use outcomes, substance use and related metrics (such as abstinence rates) were not selected as $\mathrm{P} 4 \mathrm{P}$ metrics for a number of reasons, including potential underreporting of substance use and a loss of patients to follow up. Indeed, the challenge in reaching all patients at follow up impacted the AA meeting engagement metric for youth, and was part of the reason this metric was eliminated in 2014. The treatment provider and insurance payer have also agreed that in the future, the 12 step meeting attendance metric for adults will be replaced with a program "stepdown" metric similar to the one introduced for youth. The team felt the stepdown metric is a stronger measure of patient engagement because it directly measures involvement with treatment services (as opposed to meeting attendance, which is an aftercare recommendation). In summary, our experience thus far underscores the challenges in using some types of patient metrics for P4P, particularly those collected after the care episode.

A related issue that makes implementing $\mathrm{P} 4 \mathrm{P}$ programs particularly challenging for alcohol/drug addiction treatment is the ambiguity regarding what constitutes treatment "success". There are several ways to define optimal outcomes for patients and there is no consensus in the field regarding which aspects of patient functioning are the most critical. For example, regarding substance use, some studies in the literature report complete abstinence from alcohol and drugs in the period since discharge from treatment ${ }^{[14,15]}$ whereas others report point prevalence abstinence, which covers only a portion of the follow up period. ${ }^{[16,17]}$ Other researchers 
and practitioners conceptualize significant reductions in substance use pre- to post-treatment as indicators of treatment effectiveness. ${ }^{[18]}$ As pointed out in a recent commentary by Sanghani and colleagues, different models of addiction treatment may define treatment success differently. For example, 12 step-based approaches define success in terms of complete abstinence, whereas other approaches focus more on effective management of a myriad of symptoms and/or reducing as opposed to eliminating substance use. ${ }^{[19]}$ For these reasons, creating $\mathrm{P} 4 \mathrm{P}$ programs which focus on patient outcomes will be challenging until some degree of field-wide consensus can be reached.

\subsection{Cautions and caveats}

Several caveats should be noted when interpreting these results. The results of the $\mathrm{P} 4 \mathrm{P}$ initiative thus far are descriptive only; the primary purpose of this paper was to describe the feasibility of designing and implementing a P4P program within an addiction treatment setting and provide qualitative information regarding the "wins" and challenges inherent in the process. More rigorous examination of the effectiveness of the P4P initiative in improving the quality of care and patient outcomes is a vital next step, via either a pre/post design or a randomized controlled trial. Relatedly, a weakness of the initiative reported here is that it did not utilize any objective measures of the quality of addiction treatment programming, such as urinary drug screens or measurement of chronic alcohol use via blood analysis. Such objective, physiological measures would provide the strongest evidence that treatment programming is impacting abstinence. In addition, collateral information about patient substance use obtained from family members or significant others would also speak more strongly to treatment quality from an outcome perspective. Future studies of $\mathrm{P} 4 \mathrm{P}$ in addiction treatment should explore the feasibility of such measures.

As discussed previously, the P4P initiative thus far has focused on a small set of metrics, though these metrics represent several aspects of care quality consistent with the IHI's Triple Aim. Future iterations of the initiative could expand the set of measures to include metrics that more closely represent patient outcomes (e.g., physical health, job performance or quality of life after treatment). In addition, future metrics could more directly measure the cost of care. Whereas the readmission to residential treatment metric is related to the cost of delivering addiction treatment specifically, other metrics may also capture the costs related to utilization of other healthcare services (such as hospitalizations and emergency room [ER] visits). For example, claims data of the insurance payer could be statistically analyzed to examine changes in healthcare utilization costs as a function of addiction treatment. The cost of care represents a vital piece of the patient value equation, and is just as likely as care quality to receive additional attention in the future.

\section{Conclusions}

In this paper we have outlined the development and implementation of a pilot P4P initiative by a large national alcohol/drug treatment provider through collaboration with a major insurance payer. In contrast to the treatment of a variety of chronic medical conditions, providers of addiction treatment have utilized P4P programs quite infrequently. As a result, little is known about whether implementing such programs is feasible in addiction treatment settings and whether they improve the quality and cost of care. Some studies of other chronic medical conditions suggest that P4P initiatives have the potential to improve the quality of patient care and patient outcomes, ${ }^{[4,5]}$ establishing whether these initiatives are effective with addiction treatment is important from both an individual and societal perspective. Several features of today's healthcare environment have increased expectations regarding provider accountability for the quality and cost of services, including the Affordable Care Act, the WellstoneDomenici Mental Health Parity and Addiction Equity Act, and the Institute for Healthcare Improvement (IHI)'s Triple Aim framework. As these factors gain momentum over time, addiction treatment providers will experience increased pressure to implement $\mathrm{P} 4 \mathrm{P}$ programs. Our experience suggests that successful $\mathrm{P} 4 \mathrm{P}$ implementation will require navigating a number of logistical challenges, including the identification of valid measures and finding ways to foster amicable, productive collaboration among different groups of stakeholders within the addiction treatment process.

\section{CONFlicts OF INTEREST Disclosure}

The authors declare they have no conflict of interest.

\section{REFERENCES}

[1] Cantor JC, Belloff D, Schoen C, et al. Aiming higher: Results from a state scorecard on health system performance. New York: The Commonwealth Fund; 2007 June.
[2] Berwick DM, Nolan TW, Whittington J. The triple aim: care, health and cost. Health Affairs. 2008; 27: 759-769. PMid: 18474969. http://dx.doi.org/10.1377/hlthaff .27.3.759

[3] Martin LA, Nelson EC, Lloyd RC, et al. Whole System Measures. 
Cambridge, MA: IHI Innovation Series white paper, Institute for Healthcare Improvement; 2007. Available from: www. IHI . org

[4] Van Herck P, De Smedt D, Annemans L, et al. Systematic review: Effects, design choices, and context of pay-for-performance in health care. BMC Health Services Research. 2010; 10: 247. PMid: 20731816. http://dx.doi.org/10.1186/1472-6963-10-247

[5] Houle SKD, McAlister FA, Jackevicius CA, et al. Does performance based remuneration for individual health care practitioners affect patient care? A systematic review. Ann Intern Med. 2012; 157: 889-899. PMid: 23247940. http://dx.doi.org/10.7326/0003-4819-1 57-12-201212180-00009

[6] Werner RM, Kolstad JT, Stuart EA, et al. The effect of pay-forperformance in hospitals: Lessons for quality improvement. Health Affairs. 2011; 30: 690-98. PMid: 21471490. http://dx.doi.org $/ 10.1377 /$ hlthaff .2010 .1277

[7] Garnick DW, Lee M, Horgan CM, et al. Washington Adapting Washington Circle performance measures for public sector substance abuse treatment systems. Journal of Substance Abuse Treatment. 2009; 36: 265-277. PMid: 18722075. http://dx.doi.org/10.1016/j.j sat. 2008.06 .008

[8] Garnick DW, Lee M, Horgan C, et al. Lessons from five states: Public sector use of the Washington Circle performance measures. Journal of Substance Abuse Treatment. 2011; 40: 241-254. PMid: 21257282. http://dx.doi.org/10.1016/j.jsat.2010.11.008

[9] Garnick DW, Horgan CM, Lee MT, et al. Are Washington Circle performance measures associated with decreased criminal activity following treatment? Journal of Substance Abuse Treatment. 2007; 33: 341-352. PMid: 17524596. http://dx.doi.org/10.1016/j .jsat. 2007.03 .002

[10] Garnick DW, Lee MT, O'Brien PL, et al. The Washington circle engagement performance measures' association with adolescent treatment outcomes. Drug and Alcohol Dependence. 2012b; 124: 250-258. PMid: 22364777. http://dx.doi.org/10.1016/j.drugalcde p. 2012.01.011

[11] Vandrey R, Stitzer ML, Acquavita SP, et al. Pay-for-performance in a community substance abuse clinic. Journal of Substance Abuse
Treatment. 2011; 4: 193-200. PMid: 21489739. http://dx.doi.o $\mathrm{rg} / 10.1016 / \mathrm{j} \cdot \mathrm{j}$ sat. 2011.03 .001

[12] Garner BR, Godley SH, Dennis ML, et al. Using pay for performance to improve treatment implementation for adolescent substance use disorders: results from a cluster randomized trial. Arch Pediatr Adolesc Med. 2012; 166: 938-44. PMid: 22893231. http: //dx.doi.org/10.1001/archpediatrics.2012.802

[13] Owen P. Minnesota model: description of counseling approach. In K. Carroll (Ed.). Approaches to drug abuse counseling. NIH Publication, No. 00-4151 Bethesda. MD: National Institute on Drug Abuse; 2000. p. 117-127. Available from: http://www.drugabuse.gov/ADAC /ADAC1.html

[14] Stinchfield R, Owen P. Hazelden's model of treatment and its outcome. Addictive Behaviors. 1998; 23: 669-683. http://dx.doi.o rg/10.1016/S0306-4603 (98)00015-X

[15] Klein AA, Slaymaker VJ, Dugosh KL, et al. Computerized continuing care support for alcohol and drug dependence: a preliminary analysis of usage and outcomes. Journal of Substance Abuse Treatment. 2012; 42: 25-34. PMid: 21862275. http://dx.doi.org/1 $0.1016 / j \cdot$ jsat. 2011.07 .002

[16] Hughes JR, Carpenter MJ, Naud S. Do point prevalence and prolonged abstinence measures produce similar results in smoking cessation studies? A systematic review. Nicotine and Tobacco Research. 2010; 12: 756-762. PMid: 20504946. http://dx.doi.org/10.10 93/ntr/ntq078

[17] Cohn A, Brandon T, Armeli S, et al. Real-time patterns of smoking and alcohol use: an observational study protocol of risky-drinking smokers. BMJ Open. 2015; 5: e007046. http://dx.doi .org/10 . 1136/bm jopen-2014-007046

[18] Sobell MB, Sobell LC. Obstacles to the adoption of low risk drinking goals in the treatment of alcohol problems in the United States: A commentary. Addiction Research and Theory. 2006; 14: 19-24. http://dx.doi.org/10.1080/16066350500489212

[19] Sanghani RM, Carlin AL, Moler AK. Assessing success - a commentary on the necessity of outcomes measures. Substance Abuse Treatment, Prevention, and Policy. 2015; 10: 20. PMid: 25971315. http://dx.doi.org/10.1186/s13011-015-0017-2 